\title{
ARCHITECTURAL RENEWAL: A RISING DAWN IN ILE-IFE?
}

\author{
CORDELIA O. OSASONA \\ Department of Architecture, University of Ibadan, Nigeria
}

\begin{abstract}
"Conservation", as a word frequently in use colloquially, has several nuances. In its most common usage, it is tantamount to "preservation". However, the term "architectural conservation" invariably relates to heritage structures deemed worthy of conservation-restoration intervention because of their latent iconic cultural significance. "Renewal", on its part, extends the frontiers of restoration: while putting back what was lost, it accommodates some change in the original, so as to extend the current usefulness and general relevance of the heritage structure, i.e. it is synonymous with "adaptive re-use". Even at the level of government intervention, relatively very little is going on in Nigeria in terms of heritage-structure conservation. Private (family) concern for architectural renewal of historic property is a rarity. Notwithstanding this relative neglect of Nigeria's heritage architecture, all over the country there are many worthy samples of the nation's building culture, attesting to the rich prospects of their conservation and renewal. The ancient city of Ile-Ife is not left out of this tourism (and other) potential of heritage architecture. The paper adopts the case-study approach in discussing some experimental work in architectural heritage renewal being undertaken in Ile-Ife. Specifically, two buildings, Lowa's House and the Odeyemi Family House, are critiqued, setting out the factors predisposing them to socio-cultural and architectural significance, and highlighting the unique features introduced to make them contemporarily relevant. It is submitted that, given the transformations that such interventions invariably confer (visual, utilitarian and subtly, psycho-social), it may not be far-fetched to expect a ripple effect as a fall-out of these experiments.
\end{abstract}

Keywords: architectural renewal in Ile-Ife, Ilojo Bar, Omisore family, adaptive re-use, Lowa, Nigerian Brazilian architecture.

\section{INTRODUCTION}

Worldwide, the conservation of monuments and artefacts imbued with historic and other socio-cultural significance is commonplace. Even in relatively socio-economically disadvantaged parts of the world, the prospect of appreciable economic returns on investments in conservation, has justified such efforts. Sadly, Nigeria is yet to adjust policy (and other) planning to sincerely reflect this understanding. An unfortunate attestation to this, is the 2016 demolition of "Ilojo Bar" (a Brazilian house built in 1855) - despite being declared a national monument by the National Commission for Museums and Monuments, NCMM, in 1956 [1].

Because of its significance in ethnological issues of the Yoruba (one of the three most dominant ethnicities in the country), Ile-Ife has long been on the world-map, with respect to archaeological finds and other culture-related issues. Of particular relevance to this discourse, is the fact that the ancient city also has a significant array of buildings typifying various phases in its physical evolution. Till date, the ancient city has samples of near-pristine traditional houses, British colonial buildings, British-facilitated construction (i.e. Brazilian) and Post-colonial vernacular building.

Apart from the general national apathy (mostly born of a lack of the political will to effect the needed change [2]), towns such as Ile-Ife have their own peculiar socio-cultural issues constraining investment in architectural conservation. Paramount among these are the "greener pastures" syndrome, among young people, and the lack of the funds to engage in it, 
by the, usually, aged folks left behind in such buildings [3]. This notwithstanding, in the past twenty years, the fact of a Department of Architecture being in the foremost University domiciled in the town (with Faculty concerned about the constantly perishing relics of the material culture of the town), has kick-started some attempts to intervene to arrest such a trend. These efforts have affected such buildings as the Olayinka House [4], Ile Oyinbo Moore (Ologbenla House I [4] and II [3]), the Alubarika House [4] and, more recently, the two buildings to be discussed here.

\section{THE APPROACH}

The case-study approach is adopted, as it is believed to best set out the salient, uniquely predisposing issues concerning conservation of the selected heritage buildings. In the architectural conservation specialty, the impracticability of attempting to preserve all ancient buildings, has long been agreed. As such, criteria have been adopted that restrict and justify choice of buildings worthy of conservation. Major among these are historical significance of the building, typological significance and exceptional craftsmanship [5].

The two buildings to be critiqued (Lowa's House and the Odeyemi Family House) typify one or more of these parameters. In addition, a common theme characterizes them and the initiative to put them up for restoration-renewal: the existence of a key family member, culturally exposed, passionate and wealthy enough to see the exercise through. Both buildings, till now, constitute a rallying-point for family descendants, in Nigeria and the diaspora, strengthening the basis for their renewal.

Similarly, interventions on both buildings adopt the "renewal" approach. While "architectural conservation" seeks only to ensure the well-being of a building, throughout its lifespan, "renewal" (or "adaptive re-use") goes beyond "restoration" i.e. attempting to put back what has been damaged or totally lost (through an initial total absence, or inadequacy, of preemptive conservation strategies). This approach ensures that buildings become more useful and relevant to the current needs of their owners.

\section{CASE STUDIES}

\subsection{Lowa's (Omisore Family) House, Ogbon Oya}

\subsubsection{Historical background}

The Omisore House was the personal residence of High Chief Ajani Anibijuwon Omisore, Lowa of Ife. It is situated at Ogbon Oya and is said to be between 120 and 135 years old (so was probably built between 1881 and 1896). Lowa Ajani Anibijuwon Omisore himself is said to have died in 1941, aged about 100 years old. "Lowa", in the Ife socio-political structure, is the official title given to the highest-ranking "king-maker" (emese). His most notable role is to act as regent, on the death of the traditional ruler (Ooni), till another Ooni ascends the throne. High Chief Ajani Anibijuwon Omisore became Lowa under Ooni Olubuse I and, as regent, crowned two successive Ooni (i.e. Ademiluyi and Aderemi, respectively).

Typifying Nigerian "Brazilian architecture", Lowa's House is characterized by thick cob walls, an attic, a two-storey configuration, stucco ornamentation and timber shutters. Realizing its socio-cultural iconic symbolism, it is not surprising that the Omisore Dynasty wanted Lowa's House preserved for posterity. The renewal project is being sponsored by Architect Tokunbo Omisore (the immediate Past President of the African Union of Architects, AUA), and a grandson of Lowa Omisore. 


\subsubsection{Defining characteristics}

Typically, a Brazilian house is multistoried. Each floor is characterized by a large, central corridor ("passagio", in the original Portuguese model), with living spaces flanking it on both sides. Utilities are detached, relegated to the back regions of the premises. Also, invariably, the topmost floor is an attic. Lowa's House is atypical in floor layout as, rather than display the common double-loaded corridor (popularly locally referred to as "face-me-I-face-you"), it has no internal corridors. In this aberration, coupled with being sited in Ife, it is not likely to be first-generation "Brazilian"; it can thus be reckoned "Afro-Brazilian". With a distinct attic (overlooking the approach to the premises), carved fascia-boards, decorative portal, molded window-embellishment, other mural decorations and casement (wooden-shutter or jalousie) windows, this classification does not detract from its stylistic distinctiveness.

Some unique features of Lowa's House include hardwood timber paneling of an enclosed veranda running around three sides of the first floor, linked to the ground by an external timber flanking staircase (Fig. 1). All masonry-work is of cob, with walls about $300 \mathrm{~mm}$ thick. This was plastered over with a layer (about 3" thick) of highly-granular cement-mortar (Fig. 2). The suspended floor is typical hardwood-timber planks on joists, spaced at about $75 \mathrm{~cm}$ centres, with another (internal) timber staircase linking it to the ground floor. Fenestration consists of an array of traditional windows, but mostly timber shutter panels, or slatted jalousies. All doors are wooden and paneled; the main ones are carved in ornate stylized floral-motif designs.

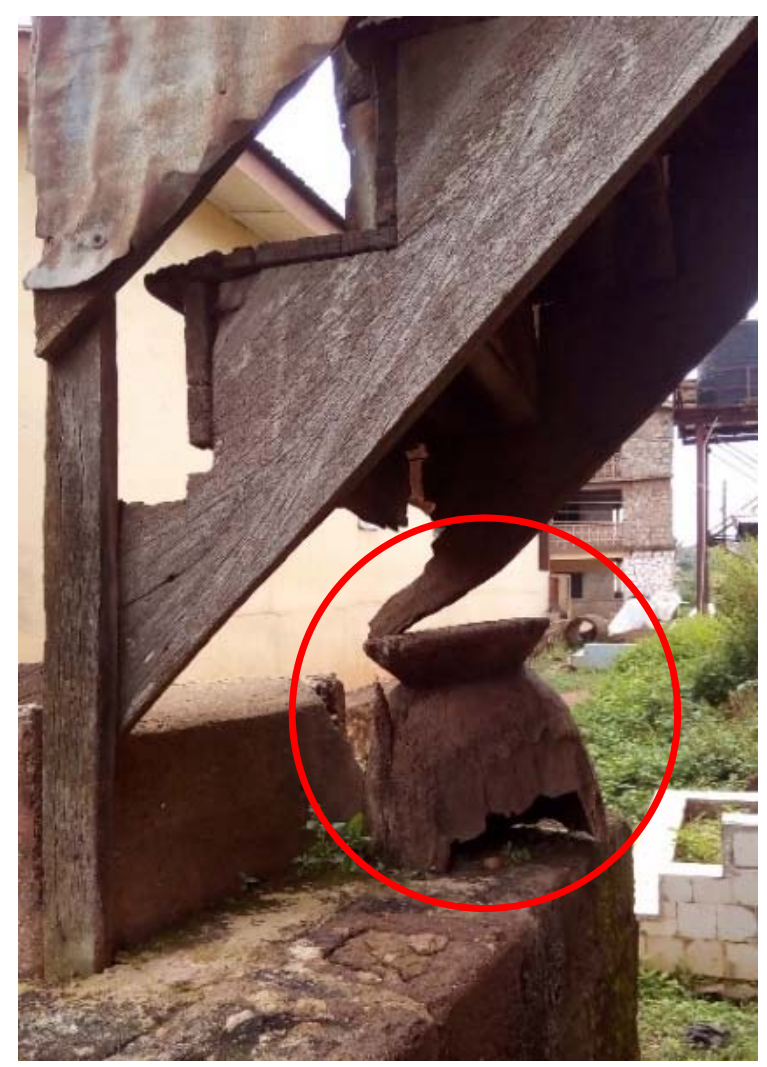

Figure 1: External staircase, supported by wooden mortar, at interface with plinth. 


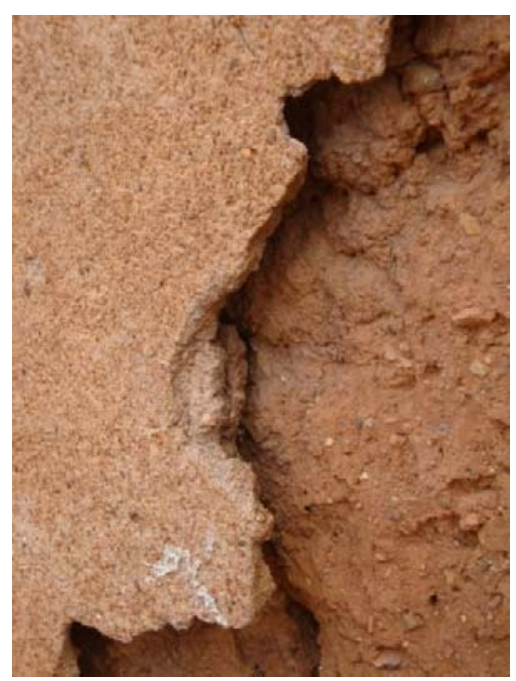

Figure 2: Deep crack in adobe wall, going into room beyond. Note extra-thick plaster-cover.

Damaged timber flooring was rampant, with the floor in the attic being merely "symbolic" (as much of it was missing). Similarly, the roof was in very bad shape. Despite the fact of most of the trusses and other members being still in good condition (since they are of durable hardwood), the cladding was dilapidated (especially in the attic) and needing an overhaul.

A major needed intervention was with respect to both the southeast and southwest wings of the compound. Built of adobe, dilapidation in both wings was very pronounced (with the southwest one totally derelict). The magnitude of work to be done in these areas - and the extended prospects of going beyond restoration - constituted the major reason for an adaptive re-use approach.

\subsubsection{Other features}

The premises contain several tombs of departed family members. The most imposing is the mausoleum of the house-owner, High Chief (Lowa) Anibijuwon Omisore. The other two in the foreground of the house, are burial vaults of his first and second sons, High Chief Shittu Olasoji Omisore and Baale Lawal Ilesanmi Omisore, respectively. Even outside this more immediate vicinity, to the forefront and in the flanks, tombs similarly dot the landscape.

Lowa Omisore House is iconic for its historical, socio-cultural and political affiliations. In addition to its stylistic attributes, it contains some relics worthy of preservation. These include furniture (seats, storage paraphernalia and a bedstead) and a customized wall-safe. Despite their quantitative insignificance, each is historically symbolic and/or artistically interesting. It was also asserted that other treasures exist in family safekeeping. This has informed contemplating a "family museum" to put them on display for public viewing.

\subsubsection{The mandate}

This was to restore the structural integrity of the main house. Additionally, worthy relics were to be identified, salvaged, and prominently displayed within the house. The dilapidated wings were to be recovered and put to new (complementary) uses. Also, part of the Omisore Family land abutting Lowa's House was to be made a burial ground for previously scattered graves 
to be transferred to. Lastly, the characteristic trado-vernacular aura of Lowa's House was to be preserved. As such, the proposal should not seek to "modernize" the main house.

To re-invigorate the premises and generally expand its present functionality, the southwest and southeast wings would be re-designed to accommodate conveniences, "curio"/crafts shops and an eatery. Car-parking was also proposed, to service the tourism angle being infused into the scheme.

With the tourism potential, it became mandatory to outline a prospective tourist's experience. A "live museum" is to be mimicked, being considered more interesting than the "traditional museum" (where artefacts are merely displayed in designated spaces). The proposal is to re-create as much of the former aura of the Lowa's home-life as possible. Treasured household relics will be contextually located. Furniture in the house (and whatever can be recalled from family members) will be restored to their former places. In essence, there will be no formal gallery; rather, every space, by its furniture, furnishings, utensils, etc., will contribute to re-enacting the life and times of High Chief Ajani Anibijuwon Omisore.

From the Carpark, access would be gained into the compound, onto a paved piazza with concrete seats. On the Ground Floor, the lounges and inner (more private) rooms can be toured. At the First Floor, there would be the interesting experience of going around three sides of the building, on the covered and enclosed, timber-panelled terrace, outside. It would afford an opportunity to view the neighbourhood in three directions. The peak of the tourist's experience above ground-floor level would be the prospect of accessing the Attic. This will afford a view of the neighbourhood in the southern direction (different from those enabled along the stretch of veranda). Going into the attic, the unusual steepness of the staircase leading to the Attic (by modern standards) is maintained; it is intended to heighten the tourist's sense of adventure; Fig. 3. Again at Ground Floor level, the tourist could use the conveniences, or visit either the eatery or the Craft Centre; he could also choose to lounge on one of the concrete seats, out in the open. Finally, he might stroll into the Burial Grounds, on the southwest flank (which would eventually route him, by an alternative gate, out of the Omisore House grounds and back to the Carpark). Figs 4 and 5.
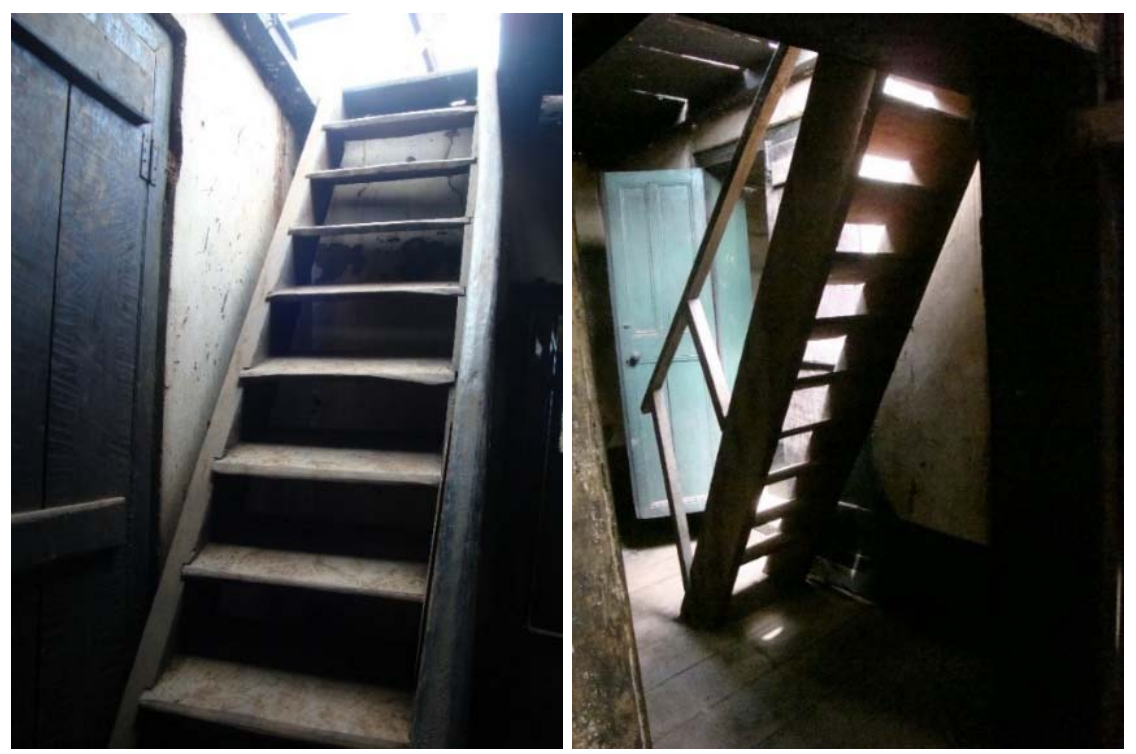

Figure 3: The attic staircase (from inside a bedroom). 


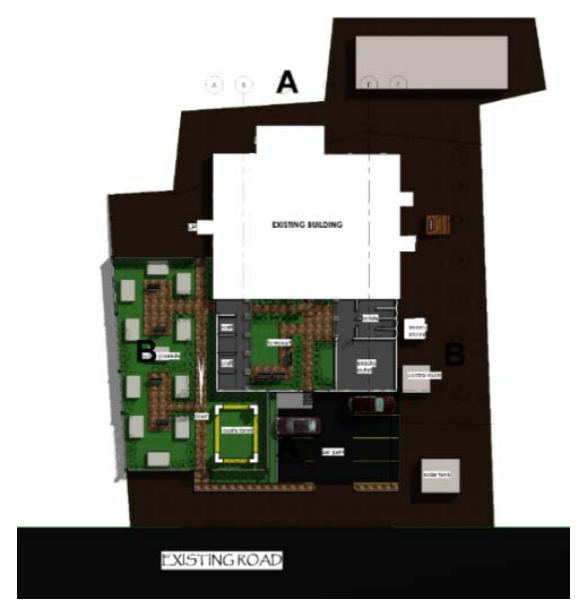

Figure 4: Proposed site layout (original).

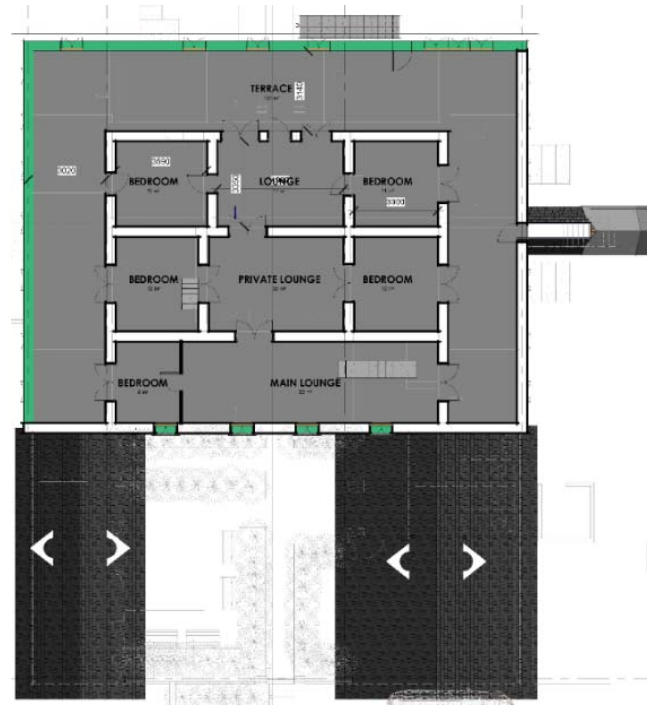

Figure 5: Plan of existing first floor. Note the encircling veranda, and roofs over proposed southern wings

\subsubsection{Work undertaken}

Even though the project is not totally over, much of the original mandate has been executed. Delays have been mostly occasioned by extended family considerations, some of them resulting in changes and actual stoppage of work. One major aspect of the original proposal that was sacrificed on the altar of such issues, was the intention to evacuate all tombs to a designated Burial Ground (leaving the foreground as a piazza with seats); the proposal was met with stiff resistance. Nonetheless, to date, appreciable progress has been made. 


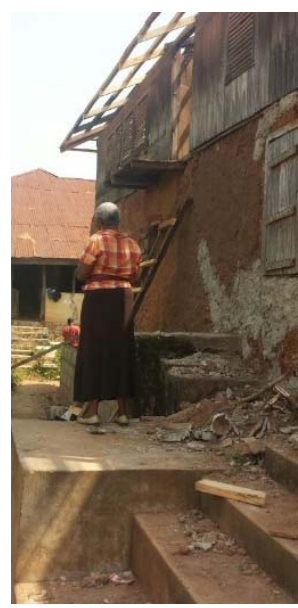

(a)

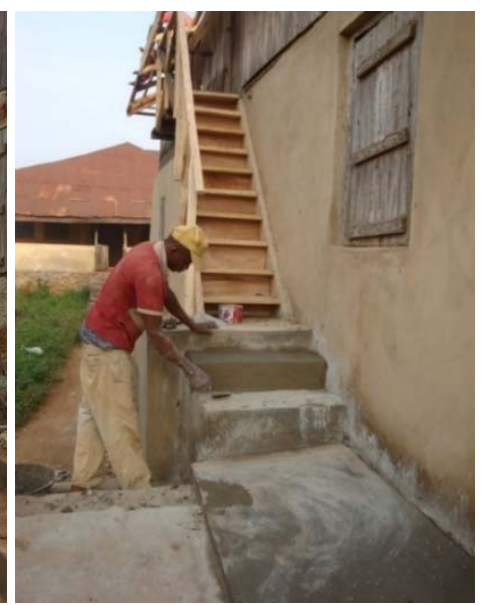

(b)

Figure 6: (a) Before re-creating the missing staircase; and (b) Ongoing replacement.

All structural defects (covering masonry-work, timber flooring, walls and staircases) have been rectified; even the missing rear staircase has been re-created; Fig. 6 . The roof over the main house was overhauled, with the corrugated zinc sheets being replaced with granular-finished corrugated aluminium sheets. Windows and doors were repaired, as necessary. Attic windows were totally replaced (though maintaining the character of the previous ones).

The overhaul of the two wings of Lowa's House complex was a major intervention. The existing dilapidated structures were demolished, giving way to an eatery and conveniences (constituting the southeast wing) and the Crafts Shops (the southwest wing). The toilets were fitted out with modern facilities, but "vernacular" surface-wiring electrification was done.

Today, Lowa's House sports an ornamental metal-grille fence, painted walls, door- and window-moulding, doors and window shutters. In the spirit of renewal (adapting the property for optimum contemporary use), glass-louvered windows were used in the toilets and the snacks retail outlet (rather than the original wooden shutters).

\subsection{Odeyemi Family House, Lokore}

\subsubsection{Background history}

This interesting building is situated at Lokore. Today, "Lokore" more generally connotes an area of the town; however, it is also a traditional title, signifying a role as spiritual head of "Odin" - one of the 16 autochthonous groups of Ile-Ife. Traditionally, the Odeyemi family was socio-culturally prominent to the point where several of them (even to date) were addressed as "oba" (king). They were also renowned for being involved in masquerade activities (featuring large masquerades like Owolanke, and smaller ones like Kinduke).

It is estimated that the house (a bungalow) was constructed between 1880 and 1900, by Logudu, the grandfather of the present custodian (whose father, Martin Odeyemi, was born there, in 1909). Chief John Agboola Odeyemi, custodian of the Odeyemi House, was 80 years old on April 4 this year; like his father before him, he was born (and grew up) in this house. 


\subsubsection{Existing building conditions}

The Odeyemi House defies stylistic classification. In its general configuration, it can be easily dismissed as "traditional". This is because several features make it typical: generally small spaces (often less than $9 \mathrm{~m}^{2}$ ); no cross-ventilation (or even basic, acceptable standards of interior lighting, owing to grossly under-sized windows); and originally no provision for in-house conveniences. However, a non-negotiable feature of such rambling, traditional buildings - the impluvium-courtyard - is conspicuously missing.

At first glance, it seemed the relatively large lobby (into which many of the surrounding spaces opened), could have been an impluvium-courtyard, once. However, at the onset of the exercise in July 2018, it was already roofed - and had been so for as long as memory served (according to Chief Odeyemi, key informant and sponsor of the intervention). Significantly, this central concourse was virtually devoid of daylighting; some light from a single Perspex sheet integrated into the roof-cladding, and through the front door (left open all day), gave weak illumination. As such, it presented a gloomy, unpleasant interior atmosphere. Fig. 7.
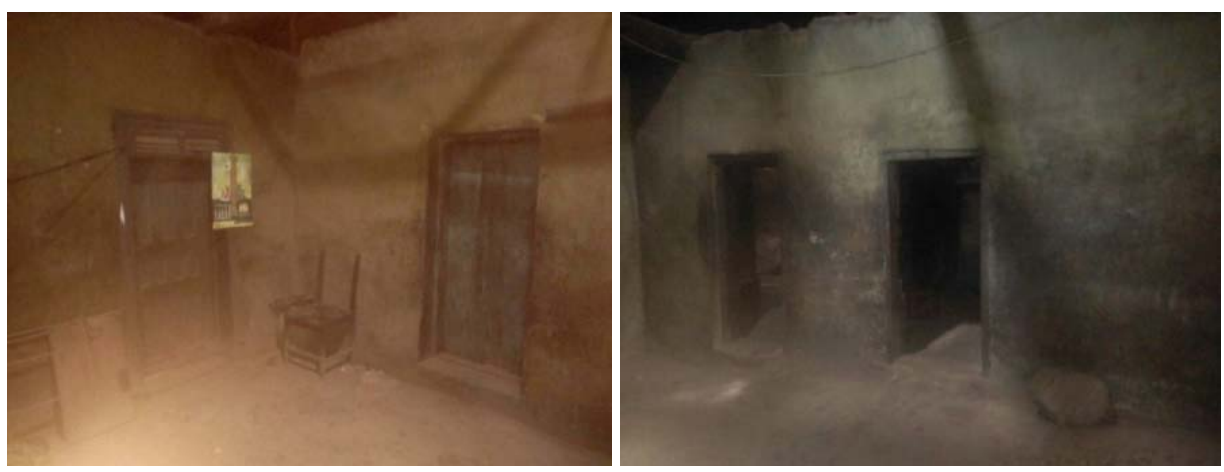

Figure 7: Interior views of the lobby, before the intervention.

\subsubsection{Structural appraisal}

All parts of the building still depicting the original work, are of thick adobe walls. However, over time, some parts had fallen away - to be selectively replaced by sandcrete blockwork. Typical of traditional building construction, many of the walls are out of plum, with several visibly undulating in surface configuration (Fig. 8(a)). Only a few structural cracks were noticed in the walls; however, much of the timberwork (doors, windows, frames, and accessories such as shelves) had become noticeably defective. Again typically, most windows were undersized and shuttered. The roof was typically of rough-sawn hardwood; however, atypically, it was very shallow in pitch.

\subsubsection{The brief}

As mentioned earlier, the Odeyemi House project was also a renewal mandate. Even though repairs were clearly indicated, a main goal of the intervention was to infuse new life into the building - to attract visits by the younger family descendants, used to the "perks" of modern living. As at the onset of the renewal intervention, only the sponsor's younger sister and a non-paying tenant, occupied the fairly sprawling, 11-room house. The following excerpt from an oral interview of Chief John A. Odeyemi, captures the salient issues of the mandate: "We want the work to be nicely, but not expensively, done - because it is 'rehabilitation' and 'modernization' work; not the construction of a new building entirely, but something that is 
adequate for now and that will also last. If there are aspects of the building you wish to preserve - for example, these windows and doors, as well as the architraves which are done well and could be preserved; if there is need for new ceilings, so be it; but it should be done in a manner that is not expensive and, at the same time, good enough for me to bring my visitors; to say 'let's go and have a drink in my grandfather's house!' My grandchildren and great grandchildren should also be able to come here..." [6].

\subsubsection{The mandate}

Next to preserving interesting features of the Odeyemi House (e.g. doorframes featuring fanlights, historically significant domestic implements and paraphernalia, and artefacts related to religious observances), a major target of the exercise was to introduce an "outdoor daylight" ambient into the central lobby - without leaving it uncovered. To achieve this, early in conceptualization, it was resolved to raise the roof over this part, to service it with clerestory windows. Thus, rather than the single roof covering the spaces beneath, a two-roof system was to be introduced. This necessarily implied a complete overhaul of the roof.

To fulfil the mandate to re-invigorate the building (and still maintain existing family relationships), partition walls were to be provided to create non-existent (or not properly articulated) in-house conveniences, and better define apartments. A functional kitchen was also to be integrated (negating traditional practices, where cooking is done outdoors, in ancillary shanty structures). See Fig. 8(b).

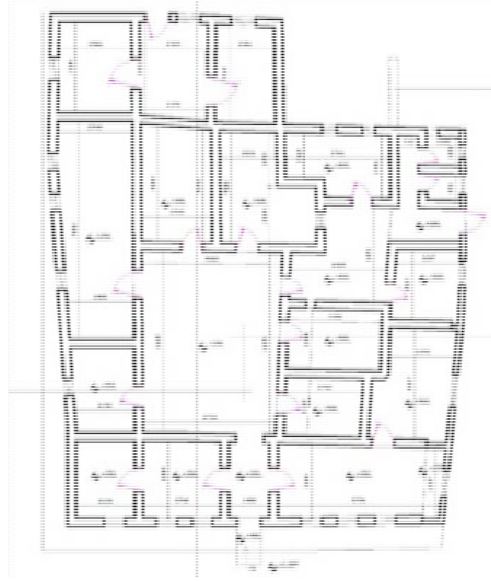

(a)

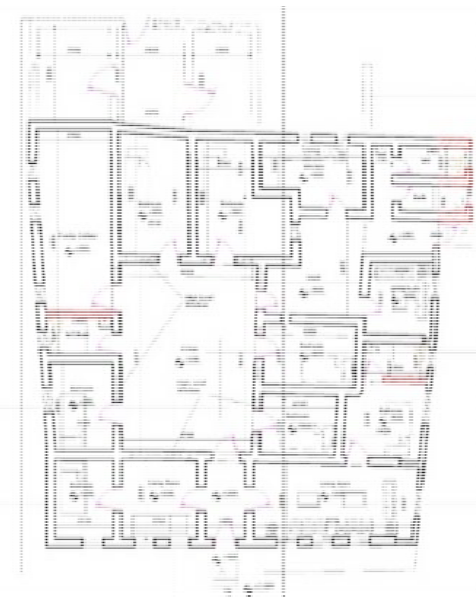

(b)

Figure 8: Floor plans of Odeyemi House. (a) Existing; and (b) Proposed amendments.

Routine repair of defective elements was proposed. In providing natural daylighting of interior spaces, it was resolved to overhaul most of the windows (since they were undersized or decrepit - or both); also, casement timber-shutters were to be replaced by glass louvre-blades. Despite all door-openings being similarly undersized, it was proposed that they be left as they were - to perpetuate the traditional concept of needing to stoop to access (or exit) living spaces. However, standard sizes were proposed for totally new doors and windows. 
Complementary to all works to be undertaken, the new-look Odeyemi House should have amenities such as piped water and electricity. Even though, at some point, the occupants had enjoyed electricity, the house had been disconnected for many years, prior to the project.

\subsubsection{Implementation}

Much of the work undertaken was quite routine. However, overhauling the roof proved more challenging than envisaged: structural challenges were duly anticipated - and prepared for; however, unforeseen climatic and social constraints surfaced to further complicate issues. (The two people who routinely used the building did not seem to understand the requirements for their speedy and total evacuation of the building; finally, even though the roof overhaul was intentionally planned for the Dry Season, flash rains surprised the exercise!). The new roof was made possible by the introduction of 8 reinforced concrete columns to hold it up; they had to be cast progressively, in synch with gradual removal of the existing roof structure.

The new-look Odeyemi House not only sports a two-roof configuration, it consists of a well-lit atrium (Fig. 9), bathrooms with WCs and shower-roses, a kitchen with a worktop and sink, a "gallery" (for family relics) and distinct bedrooms all tiled and painted. It was decided that, with people trooping in and out at will (and predisposed to running their hands along walls!), gloss paint should be used for walls, rather than the more conventional emulsion.

The exercise did not cover the rear apartment of the building, even though the two areas share a common wall; hence, the renewal intervention literally stopped at the interface. Also, a recent addition to the original mandate requested refurbishing of the two graves of family members adjacent to the house, to harmonise their appearance. See Fig. 10.
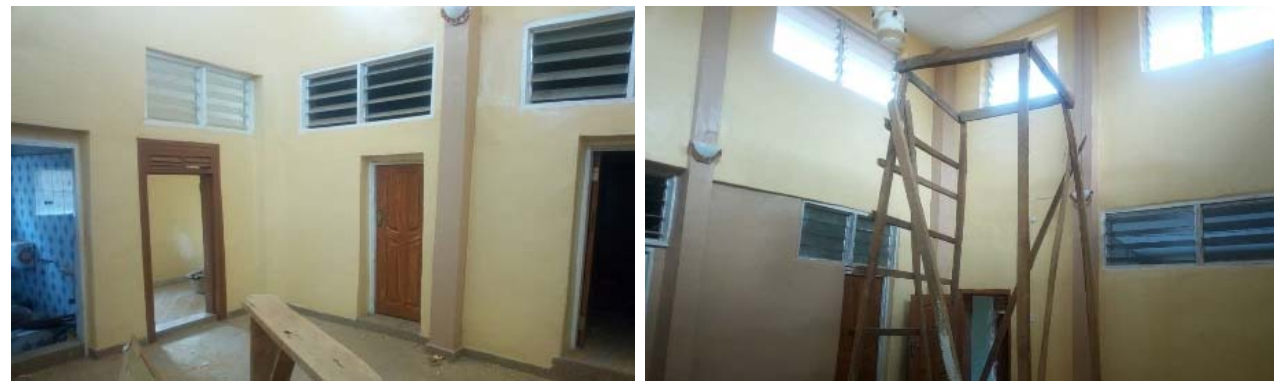

Figure 9: The well-lit, new-look atrium (lobby); work still ongoing.
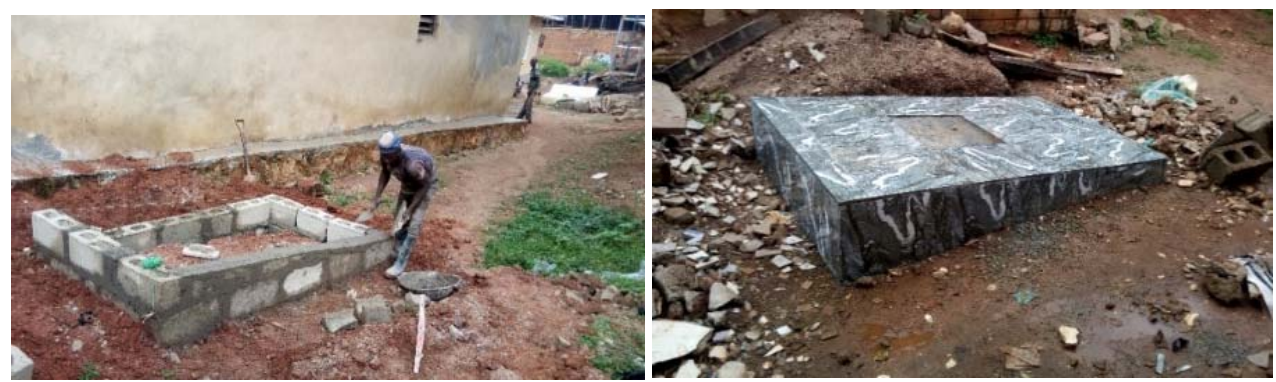

Figure 10: Ongoing refurbishing of graves of family members. 


\section{GENERAL ISSUES}

Certain issues were common to both projects. From a personal angle, given the fact that both schemes related to prominent Ife families (whose residences would normally be somewhat "elitist", even in traditional times), it was an opportunity to implement some ongoing experiments in reviving the British colonially facilitated Saro and Brazilian carved fascia-board. For Lowa's House, it was indicated, since the original roof had such fascias; some relics of this were found on the premises and, in the spirit of "restoration", exact replicas were crafted (Fig. 11). The Odeyemi House has no such history; however, it has been provided, and has succeeded in greatly setting off the new roof configuration (Fig. 12).

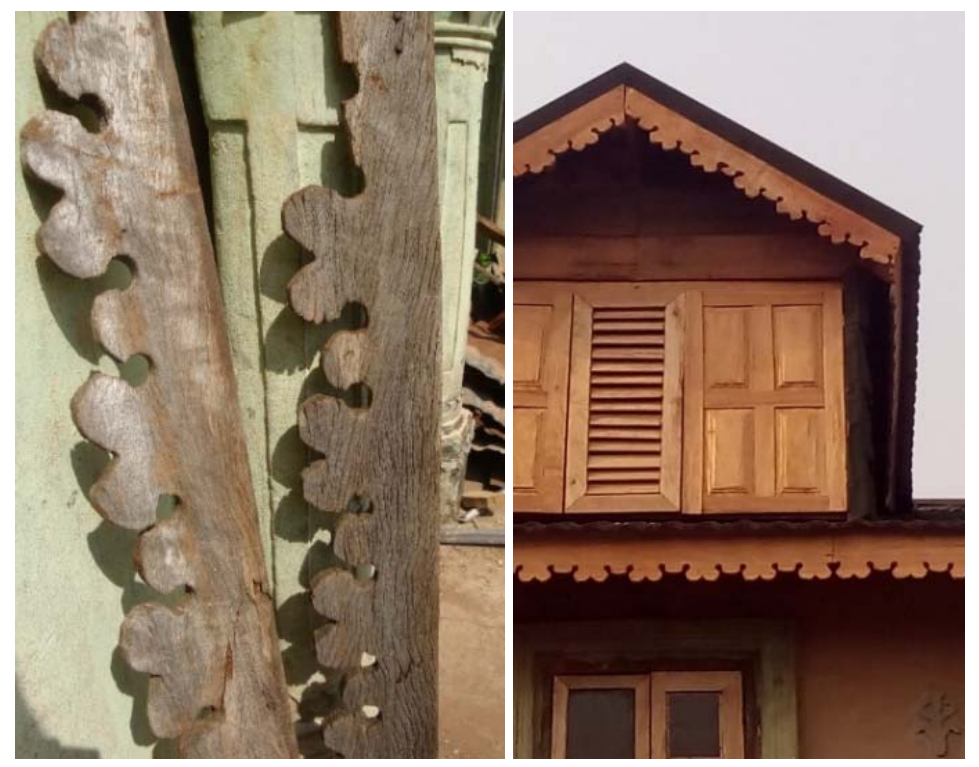

Figure 11: (a) Old (discarded); and (b) New fascias - note also, newly crafted attic shutters.

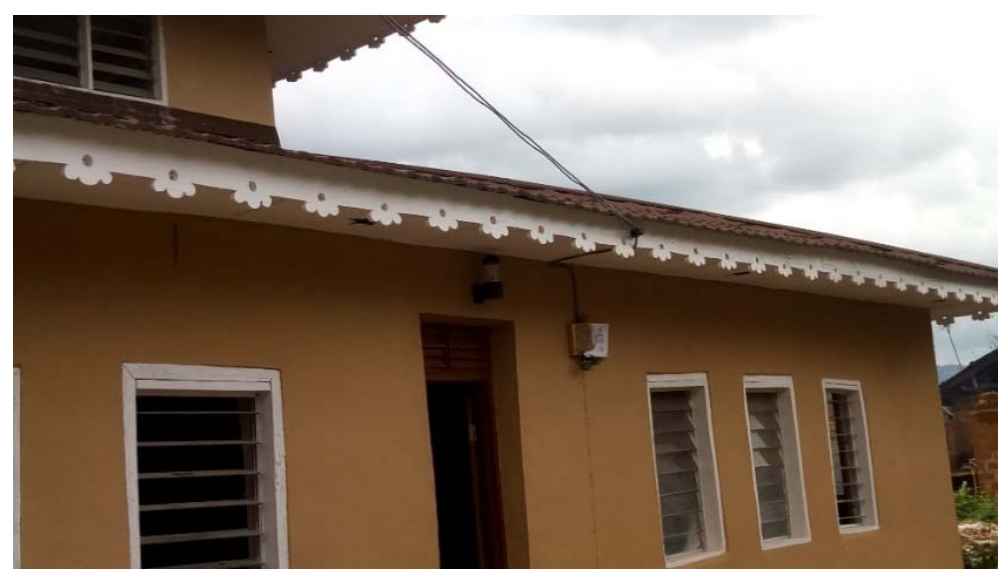

Figure 12: Fascia boards on Odeyemi House. 


\subsection{Challenges}

A common theme running through the actualization of both mandates, was the peculiar issue of extended family interference. Since in traditional Yoruba society, the "nuclear" family is something of an aberration, members of the respective extended families, believing they had a "right of relationship interest", frequently sought to interfere, by giving instructions to workers on site. With the Omisore project, there was the added complication of not just current social and political prominence, but one of sheer extensiveness of the family network; this resulted in unnecessary "reviews", outright cancellation of previously agreed works, and mid-stream introduction of fresh mandates. As such, a project that had a 10-week timeline is yet to be fully completed.

Regarding adaptations of space-use to provide in-house conveniences in Odeyemi House, there were anthropometric challenges. In two of the three provided, there was the problem of inadequate space (since the building could not be indefinitely extended). Hence, the design (to provide WC, shower and wash-hand basin) was not conventional (Fig. 13).
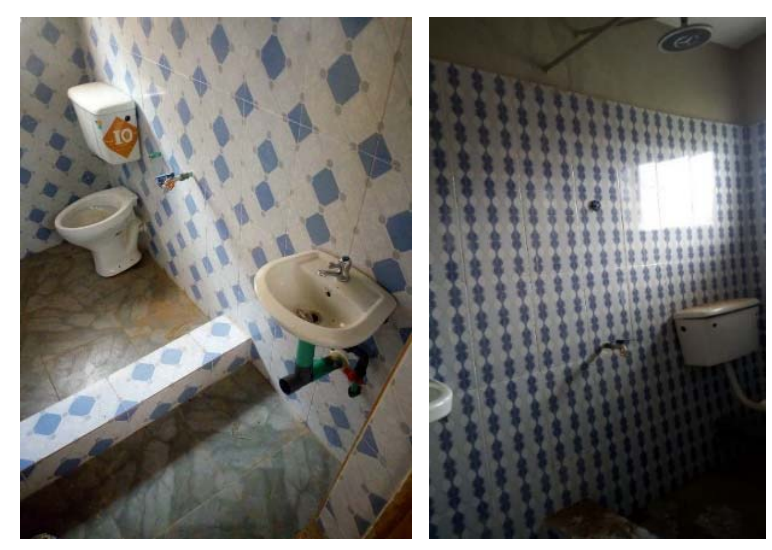

Figure 13: Two bathrooms, showing shower and WC in same enclosure, with wash-hand basin adjacent; plumbing works still ongoing.

\subsection{Impact of intervention}

The immediate physical impact of the respective restoration-renewal interventions was to infuse a "breath of fresh air" into the neighbourhood. Invariably surrounded by less prominent structures, encountering the upgraded houses produces serendipity in the casual passer-by. See Figs 14-18.

Socially, a semblance of "status repackaging" is currently ongoing in these environments. In general, long-term neighbourhood acquaintances are seeing the renewal projects as evidence of re-gained (or newly-acquired) social prominence of these families - resulting in a sense of awe of them (and possibly envy?).

With these interventions, the prospects for neighbourhood upgrade are increasing. Early feedback from Chief Odeyemi indicates a possible ripple effect of property upgrade in the vicinity, as neighbourhood childhood friends (who are still also alive and have the means) are seeing his investment in his birthplace as a challenge to their own sense of responsibility to family heritage, and may respond similarly. 

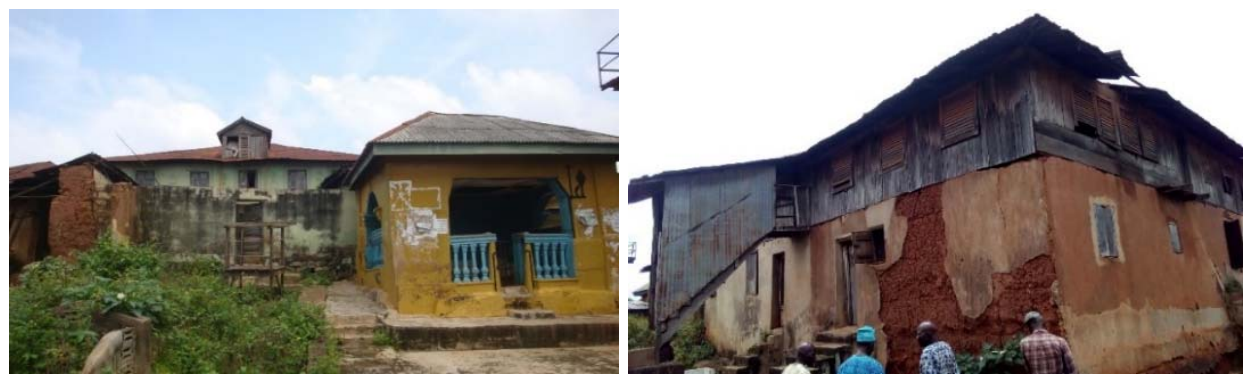

Figure 14: Lowa's (Omisore) House, at inception of project.
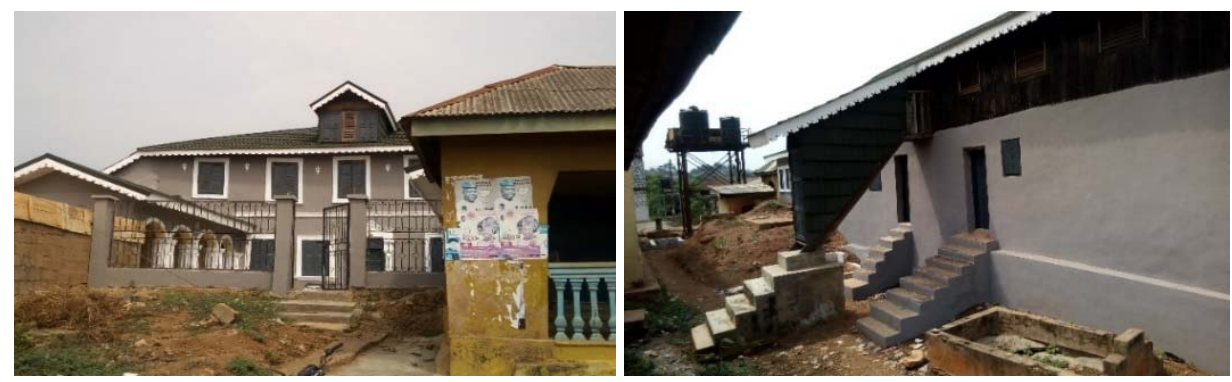

Figure 15: Lowa's (Omisore) House, close to completion.
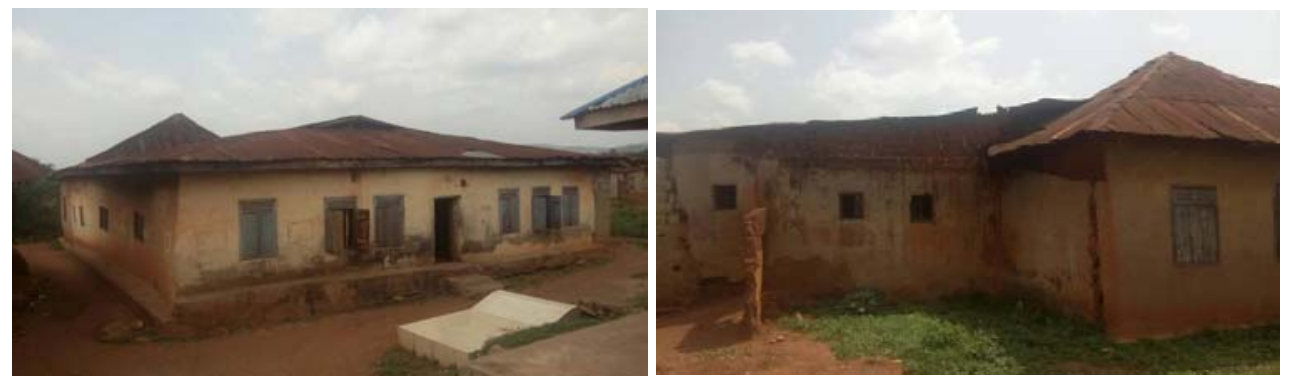

Figure 16: Approach and rear views of Odeyemi House, before the intervention.
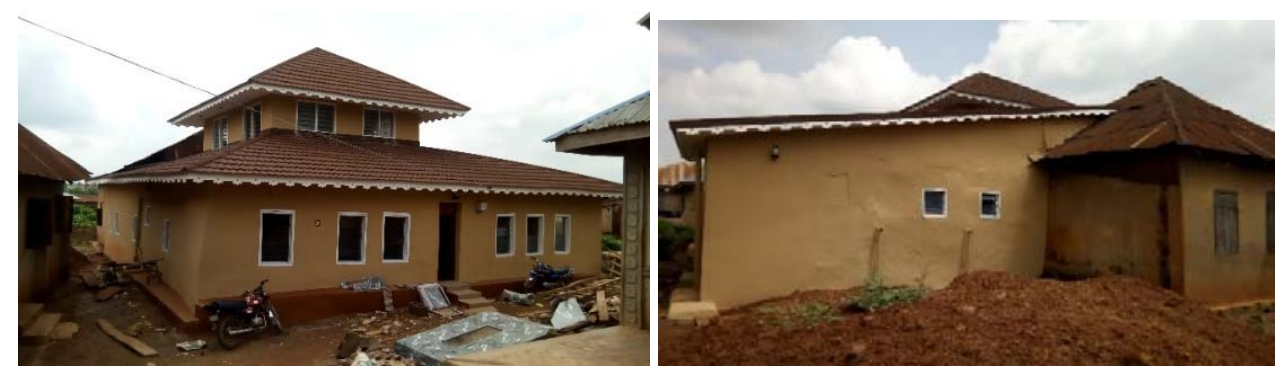

Figure 17: Approach and rear views of Odeyemi House, intervention nearing completion. 


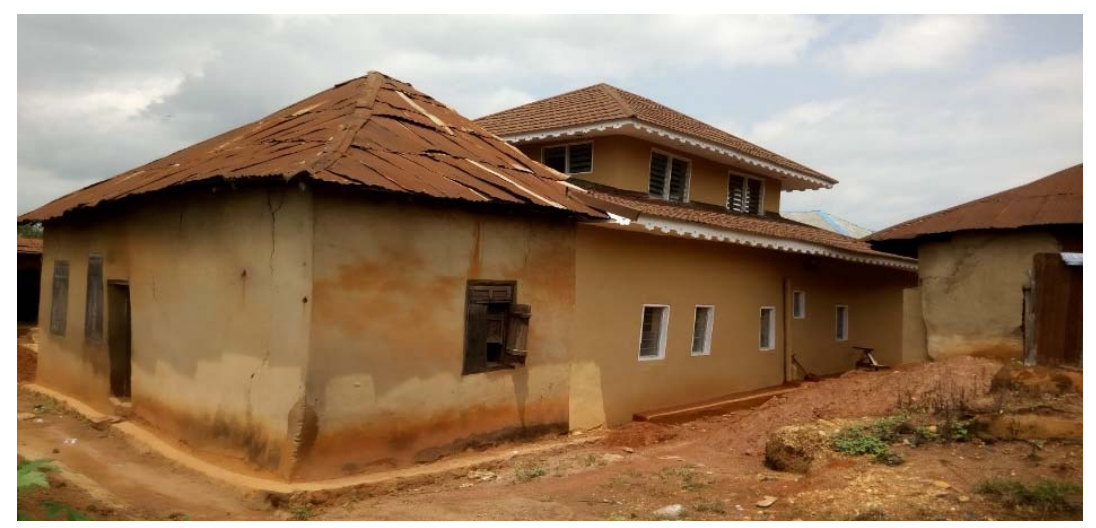

Figure 18: View of rear of Odeyemi House, showing clearly where the intervention stopped.

\section{CONCLUSION}

Even though the reality on ground in Nigeria, generally, is that there appears to be little or no regard for heritage architecture - succinctly portrayed by no meaningful government effort being deployed to its conservation [7] - there seems to be a subtle awakening of awareness in Ile-Ife. The criminal negligence being demonstrated by the agencies ostensibly conferred with the responsibility for a virile, effective drive to prevent the nation's heritage structures from perishing, is succinctly encapsulated in the tragedy that recently befell the "Ilojo Bar" in Lagos (referred to earlier).

It is hoped that whatever little efforts private individuals passionate about heritage architecture can continue to make in attempting to preserve these icons, will eventually cumulate to leave a worthy physical legacy. Ile-Ife is beginning to rally; it can only be fervently hoped that the tempo will not only be sustained, but phenomenally increased.

\section{REFERENCES}

[1] Ilojo Bar, Online. https://en.m.wikipedia.org>wiki>ilojo_bar. Accessed on: 9 Jun. 2019.

[2] Osasona, C.O., Dialectics of Nigerian architectural conservations: a case for grassroots engagement for renewal. International Journal of Heritage Architecture, 1(6), pp. 2-4, 2017.

[3] Osasona, C.O., Heritage architecture as domestic space: a tale of three buildings in IleIfe, Nigeria. International Journal of Sustainable Development and Planning, 10(1), pp. 42-65, 2015.

[4] Osasona, C.O. \& Ewemade, F.O., Upgrading Ile-Ife's vernacular architecture heritage. WIT Transactions on Structural Studies, Repairs and Maintenance of Heritage Architecture vol. 11, WIT Press: Southampton and Boston, pp. 59-70, 2009.

[5] Harvey, J., Conservation of Buildings, John Baker Ltd.: London, pp. 35-38, 1972.

[6] Odeyemi, J.A. Personal communication, 4 April 2018, Head of Odeyemi Family and Project Sponsor, Lokore, Ile-Ife, Nigeria.

[7] Osasona, C.O., Dialectics of Nigerian architectural conservations: a case for grassroots engagement for renewal. International Journal of Heritage Architecture, 1(6), pp. 4-5, 2017. 